\title{
Flavonoids of Doniophyton patagonicum (Phil.) Hieron. (Asteraceae)
}

\author{
María Elena Mendiondo, Berta Estela Juárez*
}

Facultad Ciencias Naturales e Instituto Miguel Lillo, Universidad Nacional de Tucumán, Fundación Miguel Lillo, CONICET. Miguel Lillo 205/51, (4000) San Miguel de Tucumán, República Argentina

Received 21 March 2000; accepted 12 May 2000

In memory of the late Prof. Dr. Peter Seeligmann

Keywords: Doniophyton patagonicum; Asteraceae; Flavonoids; Chemotaxonomic significance

\section{Subject and source}

Doniophyton patagonicum (Phil.) Hieron. is a small shrub, 20-30 cm high, with axillar spines, abundant yellow capitula and a plumose pappus shorter than the corolla. It grows in the biogeographic Patagonic Province (Neuquén, Río Negro, Chubut, Santa Cruz) reaching Mendoza, San Juan, La Pampa and Mendoza (Urtubey, 1996).

This plant material was collected in Mendoza and a voucher specimen is deposited at the Herbarium Ruiz Leal (MERL 7464).

\section{Previous work}

Previous work on flavonoids in other specimen of Doniophyton (Bohm and Stuessy, 1995).

\section{Present study}

Aerial vegetative parts were successively extracted with $80 \% \mathrm{MeOH}, 50 \% \mathrm{MeOH}$ and $\mathrm{MeOH}$. The concentrated extracts were run bidimensionally by PC on Whatman

\footnotetext{
*Corresponding author.

E-mail address: bejmem@csnat.unt.edu.ar (B.E. Juárez).
} 
3MM, using TBA (tert-butanol-acetic acid-water 3:1:1) and AcOH 15\% (acetic acid $15 \%$ ) as developing solvents. Structures were assigned on the basis of chromatographic behavior, color reactions with NA (Naturstoffereagenz); standard ultraviolet spectrophotometric methods (Mabry et al., 1970) and comparison with authentic samples. Doniophyton patagonicum yielded a simple pattern of flavonoids: quercetin-3-O-glucoside, quercetin-3-O-rutinoside, kaempferol-3-O-glucoside and kaempferol-3-O-rutinoside.

\section{Chemotaxonomical significance}

The genus Doniophyton is represented by two andenean-patagonic species: Doniophyton anomalum and D. patagonicum. They have slight morphological differences such as the heights of plants and the lengths of involucres. Chromosomes are $2 n=50$ in Doniophyton anomalum and $2 n=48$ in D. patagonicum (Wulff, 1990). The flavonoids of $D$. patagonicum are all typical of the Barnadesiodeae and identical to those identified in D. anomalum by Bohm and Stuessy (1995).

\section{Acknowledgements}

The study was carried out at the laboratories of the Fundación Miguel Lillo and supported in part by a Grant of the Consejo de Investigaciones Universidad Nacional de Tucumán (CIUNT).

\section{References}

Bohm, B.A., Stuessy, T.F., 1995. Syst. Bot. 20 (1), 22.

Mabry, T.J., Markham, K.R., Thomas, M.B., 1970. The Systematic Identification of Flavonoids. Springer, New York.

Urtubey, E., 1996. Flora Fanerogámica Argentina. Fascículo 31.

Wulff, A.F., 1990. Darwiniana 30, 185. 